\title{
Binary Diffusion Coefficients for Aqueous Solutions of Lactic Acid
}

\author{
Ana C. F. Ribeiro, ${ }^{1, *}$ Victor M. M. Lobo, ${ }^{1}$ Derek G. Leaist, ${ }^{2}$ \\ Joaquim J. S. Natividade, ${ }^{1}$ Luís P. Veríssimo, ${ }^{1}$ \\ Marisa C. F. Barros, ${ }^{1}$ and Ana M. T. D. P. V. Cabral ${ }^{3}$
}

Received January 13, 2005; revised March 23, 2005

\begin{abstract}
Taylor dispersion equipment installed at the University of Coimbra for the measurement of diffusion in liquids has been tested to ensure adequate accuracy and precision by measuring mutual diffusion coefficients for binary aqueous solutions of sucrose, glycine, lithium chloride, potassium chloride, and hydrochloric acid at $298.15 \mathrm{~K}$. In addition, binary mutual diffusion coefficients for aqueous solutions of lactic acid (not previously reported in the literature) have been measured at 298.15 and $303.15 \mathrm{~K}$ and concentrations up to $0.20 \mathrm{~mol}-\mathrm{dm}^{-3}$.
\end{abstract}

KEY WORDS: Weak electrolyte; diffusion coefficient; aqueous lactic acid solutions.

\section{INTRODUCTION}

Studies of diffusion in electrolyte solutions are important for fundamental reasons, such as understanding solution structure and ionic mobilities, and for practical reasons, such as developing models of corrosion and other ionic processes. For example, diffusion data for aqueous solutions of lactic acid and other organic acids are required in order to adequately understand the corrosion of dental metallic alloys in the oral environment. ${ }^{(1,2)}$ Although some studies of the simultaneous diffusion of $\mathrm{NaCl}$, lactic acid, and water in food products have been carried out, to the best of our knowledge no data are available for the diffusion coefficients of lactic acid in aqueous solutions.

Many techniques are used to investigate diffusion in solutions. In this study, Taylor dispersion equipment recently installed at the University of Coimbra is used

\footnotetext{
${ }^{1}$ Department of Chemistry, University of Coimbra, 3004 - 535 Coimbra, Portugal; e-mail: anacfrib@ ci.uc.pt.

${ }^{2}$ Department of Chemistry, University of Western Ontario, London, Ontario, Canada N6A 5B7.

${ }^{3}$ Faculty of Pharmacy, University of Coimbra, 3000 - 295 Coimbra, Portugal.
} 
to measure binary mutual diffusion coefficients, $D$, for aqueous lactic acid solutions at 298.15 and $303.15 \mathrm{~K}$. The concentration dependence of $D$ is compared with predictions for dilute solutions of a partially dissociated electrolyte. In addition, the accuracy of the Taylor diffusion measurements is assessed by measuring binary mutual diffusion coefficients for aqueous solutions of potassium chloride, lithium chloride, glycine, sucrose, and hydrochloric acid at $298.15 \mathrm{~K}$ for comparison with previously reported $D$ values measured by accurate optical interferometric and conductimetric techniques.

\section{EXPERIMENTAL}

Potassium chloride (Riedel-de-Haen, pro analysi $>99.5 \%$ ), lithium chloride (Riedel-de-Haen, pro analysi $>98.5 \%$ ), glycine (Riedel-de-Haen), sucrose (Sigma, pro analysi $>99 \%$ ), aqueous hydrogen chloride (Sociedade Portuense de Drogas, $33.5 \mathrm{wt} \% \mathrm{HCl}$ ), and aqueous lactic acid (Riedel-de-Haen, $92.1 \mathrm{wt} \%$ lactic acid) were used as received. The solutions for the diffusion measurements were prepared in calibrated volumetric flasks using bidistilled water. The solutions were freshly prepared and deaerated for about $30 \mathrm{~min}$ before each set of runs. The solutions were titrated to determine the concentration after they were degassed.

The Taylor dispersion method for measuring diffusion coefficients is based on the work carried out by G. I. Taylor in 1953 and $1954 .^{(3-5)}$ This reliable and convenient technique ${ }^{(6-11)}$ is based on the dispersion of a very small amount of solution injected into a laminar carrier stream of solvent or solution of different composition flowing through a long capillary tube.

The length of the capillary tube was determined by direct measurement, by stretching it out lengthwise in a large hall and using two high quality theodolytes and appropriate mirrors capable of focusing the capillary tube ends very accurately. This technique gave a tube length of $3.2799( \pm 0.0001) \times 10^{3} \mathrm{~cm}$, in agreement with less-precise check measurements using a good quality measuring tape. The radius of the tube was obtained by accurately weighing (resolution $0.1 \mathrm{mg}$ ) the tube when empty and when filled with distilled water of known density. This procedure gave a tube radius of $0.05570( \pm 0.00003) \mathrm{cm}$.

At the start of each run, a 6-port Teflon injection valve (Rheodyne, model 5020 ) was used to introduce $0.063 \mathrm{~cm}^{3}$ of solution into the laminar carrier stream of slightly different composition. A flow rate of $0.23 \mathrm{~cm}^{3} \mathrm{~min}^{-1}$ (corresponding to 3.5 rotations per minute of the peristaltic pump head) has been used and was controlled by a metering pump (Gilson model Miniplus 3 ) to give retention times of about $8 \times 10^{3} \mathrm{~s}$. The dispersion tube and the injection valve were kept at 298.15 and $303.15 \mathrm{~K}( \pm 0.01 \mathrm{~K})$ in an air thermostat.

Dispersion of the injected samples was monitored using a differential refractometer (Waters model 2410) at the outlet of the dispersion tube. Detector voltages, $V(t)$, were measured at accurately timed $5 \mathrm{~s}$ intervals with a digital 
voltmeter (Agilent $34401 \mathrm{~A}$ ) with an IEEE interface. Binary diffusion coefficients were evaluated by fitting the dispersion equation

$$
V(t)=V_{0}+V_{1} t+V_{\max }\left(t_{\mathrm{R}} / t\right)^{1 / 2} \exp \left[-12 D\left(t-t_{\mathrm{R}}\right)^{2} / r^{2} t\right]
$$

to the detector voltages. The additional fitting parameters were the mean sample retention time, $t_{R}$, peak height, $V_{\max }$, baseline voltage, $V_{0}$, and baseline slope, $V_{1}$.

The concentrations of the injected solutions $(\bar{c}+\Delta c)$ and the carrier solutions $(\bar{c})$ differed by $\pm 0.150 \mathrm{~mol} \mathrm{dm}^{-3}$ or less. Solutions of different composition were injected into each carrier solution to confirm that the measured diffusion coefficients were independent of the initial concentration difference and therefore represented the differential value of $D$ at the carrier-stream composition.

\section{RESULTS}

\subsection{Tests of the Dispersion Equipment}

Binary aqueous solutions of sucrose, glycine, $\mathrm{LiCl}, \mathrm{KCl}$, and $\mathrm{HCl}$ were used to test the operation of the dispersion equipment. These systems were chosen because their diffusion coefficients are accurately known from conductimetric and optical interferometric measurements (uncertainties $<0.5 \%)^{(12-17)}$ and span a useful range of $D$ values from about $0.5 \times 10^{-9}$ to $3.0 \times 10^{-9} \mathrm{~m}^{2}-\mathrm{s}^{-1}$. Table I gives the concentrations of the test solutions that were used, the mean $D$ values at $298.15 \mathrm{~K}$ determined from four to six replicate dispersion profiles, and their relative deviations from the literature $D$ values tabulated. The reproducibility of these results was usually within $\pm 99 \%$. Comparison of the results suggests an acceptable uncertainty of $1-2 \%$ for the Taylor $D$ values reported here, having in mind that $1-2 \%$ uncertainty is typical for Taylor dispersion measurements. Naturally, the diffusion coefficients for $\mathrm{KCl}$ solutions were calculated on the basis of the capillary tube radius, very accurately measured, as mentioned before. The

Table I. Mean Diffusion Coefficients at 298.15 K Measured by Taylor Dispersion for $0.100 \mathrm{~mol} \mathrm{dm}^{-3}$ Test Solutions and Previous Literature Values

\begin{tabular}{lcccc}
\hline $\begin{array}{c}\text { Test } \\
\text { solution }\end{array}$ & $\Delta c^{a} / \mathrm{mol} \mathrm{dm}^{-3}$ & $D / 10^{-9} \mathrm{~m}^{2} \mathrm{~s}^{-1}$ & $D_{\mathrm{Lit}}{ }^{b} / 10^{-9} \mathrm{~m}^{2} \mathrm{~s}^{-1}$ & $\left(D-D_{\mathrm{Lit}}\right) / D_{\mathrm{Lit}} \%$ \\
\hline Sucrose & 0.05 & 0.526 & 0.522 & 0.8 \\
Glycine & 0.05 & 1.047 & 1.041 & 0.6 \\
$\mathrm{LiCl}$ & 0.05 & 1.251 & 1.269 & -1.4 \\
$\mathrm{KCl}$ & 0.05 & 1.809 & 1.838 & -1.6 \\
$\mathrm{HCl}$ & 0.05 & 3.013 & 3.050 & -1.2 \\
\hline
\end{tabular}

${ }^{a} \Delta c$ represents the difference between the flow and injection solutions (see above), respectively.

${ }^{b} D_{\text {Lit }}$ represents the literature diffusion coefficients values. ${ }^{(12-17)}$ 
Table II. Mean Diffusion Coefficients of Aqueous Lactic Acid Solutions Measured by the Taylor Technique at $298.15 \mathrm{~K}$

\begin{tabular}{cccc}
$\begin{array}{c}\text { Flow solution } \\
\text { concentration } \bar{c} / \mathrm{mol} \mathrm{dm}^{-3}\end{array}$ & $\Delta c^{a} / \mathrm{mol} \mathrm{dm}^{-3}$ & $\begin{array}{c}\text { Number } \\
\text { of injections }\end{array}$ & $D / 10^{-9} \mathrm{~m}^{2} \mathrm{~s}^{-1}$ \\
\hline 0.0025 & 0.0025 & 4 & 0.993 \\
0.005 & 0.005 & 4 & 0.967 \\
0.008 & 0.006 & 4 & 0.952 \\
0.010 & 0.005 & 4 & 0.938 \\
0.030 & 0.050 & 4 & 0.890 \\
0.050 & 0.025 & 4 & 0.873 \\
0.100 & 0.150 & 4 & 0.848 \\
0.150 & 0.050 & 4 & 0.838 \\
0.200 & 0.050 & 5 & 0.824
\end{tabular}

${ }^{a}$ See Table I.

fact that those values coincided with literature values, which are considered highly reliable, also proves that our value for the capillary radius is adequate.

\subsection{Diffusion Coefficients of Aqueous Lactic Acid Solutions}

The Taylor dispersion equipment was used to measure diffusion coefficients for aqueous lactic acid solutions at 298.15 and $303.15 \mathrm{~K}$ and concentrations from 0.0025 to 0.20 mol- $\mathrm{dm}^{-3}$. Tables II and III give the average $D$ value for each carrier solution determined from four to five profiles generated by injecting samples that were more or less concentrated than the carrier solution. Good reproducibility was observed, within $\pm 99 \%$. From a simple Arrhenius-type equation ${ }^{(6)}$ and from the diffusion coefficients at the two different temperatures, Tables II and III, we calculated the following activation energies, all in $\mathrm{kJ} \mathrm{mol}^{-1}: 21.2$ for $0.005 \mathrm{~mol} \mathrm{dm}^{-3}$;

Table III. Mean Diffusion Coefficients, $D$, of Aqueous Lactic Acid Solutions Measured by the Taylor Technique at $303.15 \mathrm{~K}$

\begin{tabular}{cccc}
$\begin{array}{c}\text { Flow solution } \\
\text { concentration } \bar{c} / \mathrm{mol} \mathrm{dm}^{-3}\end{array}$ & $\Delta c^{a} / \mathrm{mol} \mathrm{dm}^{-3}$ & $\begin{array}{c}\text { Number } \\
\text { of injections }\end{array}$ & $D / 10^{-9} \mathrm{~m}^{2} \mathrm{~s}^{-1}$ \\
\hline 0.005 & 0.005 & 4 & 1.127 \\
0.008 & 0.006 & 4 & 1.078 \\
0.010 & 0.005 & 4 & 1.045 \\
0.030 & 0.050 & 4 & 1.056 \\
0.050 & 0.025 & 4 & 0.947 \\
0.100 & 0.150 & 4 & 0.920 \\
0.150 & 0.050 & 4 & 0.916 \\
0.200 & 0.050 & 5 & 0.908 \\
\hline
\end{tabular}

${ }^{a}$ See Table I. 
17.2 for $0.008 \mathrm{~mol} \mathrm{dm}^{-3} ; 15.0$ for $0.010 \mathrm{~mol} \mathrm{dm}^{-3} ; 11.4$ for $0.050 \mathrm{~mol} \mathrm{dm}^{-3} ; 11.4$ for $0.100 \mathrm{~mol} \mathrm{dm}^{-3} ; 12.3$ for $0.150 \mathrm{~mol} \mathrm{dm}^{-3}$ and 13.5 for $0.200 \mathrm{~mol} \mathrm{dm}^{-3}$.

\section{DISCUSSION}

Dissociation influences the rate of diffusion of a weak electrolyte in two important ways. By increasing the number of free solute species, dissociation increases the chemical potential gradient that drives the solute through the solvent. On the other hand, because the movement of two separate ions experiences more frictional resistance than the transport of a single molecular species, dissociation tends to reduce the overall mobility of the weak electrolyte component. These effects combined with small corrections for electrophoresis and nonideal thermodynamic behavior and viscosity changes lead to the limiting expression

$$
D=\frac{2(1-\alpha) D_{\mathrm{m}}^{0}+\alpha\left(D_{ \pm}^{0}+\Delta_{1}+\Delta_{2}\right)}{2-\alpha}\left(1+\alpha \frac{d \ln y_{ \pm}}{d \ln c}\right) \frac{1}{\eta_{\mathrm{r}}}
$$

for the diffusion coefficient for dilute solutions of a 1:1 weak electrolyte. ${ }^{(18,19)}$

Values of $\alpha$, the degree of dissociation, required for the analysis of the data were calculated using $K_{a}=1.374 \times 10^{-4} \mathrm{~mol} \mathrm{dm}^{-3}$ for the dissociation constant of this acid at $298.15 \mathrm{~K} .{ }^{(20)}$ Ionic activity coefficients at the same temperature were computed from the convenient relation ${ }^{(18)}$

$$
\ln y_{ \pm}=-1.17 I^{1 / 2} /\left(1+I^{1 / 2}\right)
$$

where $I=\alpha c$ is the ionic strength in units of $\mathrm{mol} \mathrm{dm}^{-3}$. Since the solutions were dilute, the activity coefficient of molecular lactic acid was set equal to unity.

$D_{\mathrm{m}}^{0}$ and $D_{ \pm}^{0}$ denote the limiting diffusion coefficients of the molecular and ionized forms of the electrolyte. We used $D_{\mathrm{m}}^{0}=0.888 \times 10^{-9} \mathrm{~m}^{2} \mathrm{~s}^{-1}$ for the diffusivity of molecular lactic acid at $298.15 \mathrm{~K}$. This was obtained by extrapolation to zero concentration the diffusion coefficients measured at concentrations where ionization is almost negligible $\left(c>0.05 \mathrm{~mol} \mathrm{dm}^{-3}\right){ }^{(18,21)} D_{ \pm}^{0}$ can be calculated from the Nernst equation

$$
D_{ \pm}^{0}=\frac{2 \mathrm{RT}}{F^{2}} \frac{\lambda_{+}^{0} \lambda_{-}^{0}}{\lambda_{+}^{0}+\lambda_{-}^{0}}
$$

if the limiting ionic conductances are known. Using $\lambda^{0}\left(H^{+}\right)=349.81 \mathrm{~S} \mathrm{~cm}^{2}$ $\mathrm{s}^{-1(18)}$ and $\lambda^{0}$ (lactate) $=38.7 \mathrm{~S} \mathrm{~cm}^{2} \mathrm{~s}^{-1(22)}$ at $298.15 \mathrm{~K}$, the diffusion coefficient of the fully ionized acid at this temperature is $D_{ \pm}^{0}=1.855 \times 10^{-9} \mathrm{~m}^{2} \mathrm{~s}^{-1}$.

The terms $\Delta_{1}$ and $\Delta_{2}$ appearing in Eq. (2) are the Onsager-Fuoss terms that reflect changes in the effective mobilities of the ions caused by electrophoretic 
interactions. For aqueous solutions at $298.15 \mathrm{~K}$, these terms are evaluated using

$$
\begin{aligned}
& \Delta_{1}=-8.07 \times 10^{6}\left(\frac{\lambda_{+}^{0}-\lambda_{-}^{0}}{\lambda_{+}^{0}+\lambda_{-}^{0}}\right)^{2} \frac{I^{1 / 2}}{1+\kappa a} \\
& \Delta_{2}=\frac{8.77 \times 10^{-21}}{a^{2}}\left(\frac{\kappa a \exp (\kappa a)}{1+\kappa a}\right)^{2} \operatorname{Ei}(2 \kappa a)
\end{aligned}
$$

where $a$ is the ion size parameter in $\mathrm{cm}, \kappa$ in $\mathrm{cm}^{-1}$ is given by

$$
\kappa=3.29 \times 10^{7} I^{1 / 2}
$$

and

$$
\operatorname{Ei}(x)=-0.5772-\ln x+x-\frac{x^{2}}{2(2 !)}+\frac{x^{3}}{3(3 !)}-\cdots
$$

To estimate the electrophoretic terms, the reasonable value $5 \times 10^{-8} \mathrm{~cm}$ was chosen for the ion size parameter. ${ }^{(18)}$ An accurate value of $a$ is not required given the relatively small magnitude of the electrophoretic corrections for this system.

In Table IV our results for aqueous lactic acid are compared with the results predicted from the above model. The measured and predicted diffusion coefficients are in excellent agreement (within $0.3 \%$ ) for lactic acid concentrations $\leq 0.01 \mathrm{~mol}$ $\mathrm{dm}^{-3}$. At higher concentrations, the predicted $D$ values are $2-4 \%$ too high. This is understandable if we take into account the well-known fact that the relative viscosity term in Eq. (2) generally overcorrects the predicted $D$ values for changes

\begin{tabular}{|c|c|c|c|c|c|c|c|c|}
\hline$c / \mathrm{mol} \mathrm{dm}^{-3}$ & $\alpha$ & $\begin{array}{c}-d \ln y_{ \pm} / \\
d \ln c\end{array}$ & $-10^{9} \Delta_{1}{ }^{a}$ & $10^{9} \Delta_{2}{ }^{a}$ & $1 / \eta_{\mathrm{r}}^{b}$ & $10^{9} D_{\text {calc }^{a, c}}{ }^{a, c}$ & $10^{9} D_{\text {calc }^{a}}{ }^{a}$ & $\begin{array}{c}\Delta D / \\
D_{\text {calc }}{ }^{d} \%\end{array}$ \\
\hline 0.0025 & 0.208 & 0.013 & 0.011 & 0.001 & 1.000 & 0.996 & 0.996 & -0.3 \\
\hline 0.005 & 0.152 & 0.015 & 0.014 & 0.001 & 0.999 & 0.964 & 0.963 & +0.4 \\
\hline 0.008 & 0.123 & 0.017 & 0.015 & 0.002 & 0.998 & 0.948 & 0.946 & +0.6 \\
\hline 0.010 & 0.110 & 0.018 & 0.016 & 0.002 & 0.998 & 0.941 & 0.939 & -0.1 \\
\hline 0.030 & 0.065 & 0.024 & 0.022 & 0.003 & 0.993 & 0.918 & 0.912 & -2.4 \\
\hline 0.050 & 0.051 & 0.027 & 0.024 & 0.003 & 0.990 & 0.912 & 0.901 & -3.1 \\
\hline 0.100 & 0.036 & 0.031 & 0.028 & 0.005 & 0.977 & 0.904 & 0.883 & -3.9 \\
\hline 0.150 & 0.030 & 0.034 & 0.031 & 0.005 & 0.966 & 0.901 & 0.870 & -3.7 \\
\hline 0.200 & 0.026 & 0.037 & 0.033 & 0.006 & 0.955 & 0.899 & 0.859 & -4.1 \\
\hline
\end{tabular}

Table IV. Degrees of Dissociation, $\alpha$, Thermodynamic Factors, $-d \ln y_{ \pm} / d \ln c$, Electrophoretic Corrections, $\Delta_{1}$ and $\Delta_{2}$, Inverse of Relative Viscosities, $1 / \eta_{r}$, and Diffusion Coefficients for Aqueous Solutions of Lactic Acid at 298.15 K Calculated by Eq (2), $D_{\text {calc }}$

${ }^{a}$ units $\mathrm{m}^{2} \mathrm{~s}^{-1}$.

${ }^{b}$ Values estimated by using a polynomial equation fitted to experimental data from Ref. ${ }^{(20)}$

${ }^{c}$ Diffusion coefficients calculated by using Eq. (2) without the term, $1 / \eta_{r}$.

${ }^{d} D / D_{\text {calc }}$ represents the relative deviations between $D_{\exp }$ (Table II) and $D_{\text {calc }}$ (Eq. 2) values. 
in mobilities caused by changes in the bulk solution viscosity. Similar conclusions should be expected for lactic acid solutions at $303.15 \mathrm{~K}$, but diffusion coefficient predictions are not feasible because the limiting conductivity of the lactate ion has not been measured at this temperature.

\section{CONCLUSIONS}

An acceptable inaccuracy of $1-2 \%$ of the Taylor measurements was estimated.

Diffusion coefficients have been measured for aqueous solutions of lactic acid to provide transport data to help model the corrosion of metallic dental alloys. The equation developed for weak acid diffusion adequately describes the concentration dependence of mutual diffusion coefficients for lactic acid on lower concentrations $\left(c \leq 0.01 \mathrm{~mol} \mathrm{dm}^{-3}\right)$.

\section{ACKNOWLEDGMENTS}

Financial support from POCTI/QUI/39593/2001 and POCTI/35415/QUI/ 2000 is gratefully acknowledged. One of us (A. Ribeiro) is grateful to Prof. V. Vitagliano and Prof. O. Ortona, from the Chemistry Department of Naples University Federico II, Italy, for their valuable comments on the different species in these solutions. We are also grateful to Dr. Manuel Vicente and Dr. Jorge Santos of the Department of Topography of the University of Coimbra, Portugal, for their contribution to the accurate measurement of the length of the capillary tube.

\section{REFERENCES}

1. M. Koike and H. Fujii, Biomaterials 22, 2931 (2001).

2. P. E. Gerla and A. C. Rubiolo, J. Food Eng. 56, 401 (2003).

3. G. I. Taylor, Proc. R. Soc. Lond. A 219, 186 (1953).

4. G. I. Taylor, Proc. R. Soc. Lond. A 223, 446 (1954).

5. G. I. Taylor, Proc. R. Soc. Lond. A 225, 473 (1954).

6. H. J. V. Tyrrell and K. R. Harris, Diffusion in Liquids (Butterworths, London, 1984).

7. D. G. Leaist, Phys. Chem. Chem. Phys. 4, 4732 (2002).

8. L. Hao and D. G. Leaist, J. Chem. Eng. Data 41, 210 (1996).

9. D. G. Leaist, J. Chem. Soc., Faraday Trans. 87, 597 (1991).

10. J. Barthel, H. J. Gores, C. M. Lohr, and J. J. Seidl, J. Solution Chem. 25, 921 (1996).

11. D. G. Leaist and L. Hao, J. Solution Chem. 21, 345 (1992).

12. L. J. Gosting and M. S. Morris, J. Am. Chem. Soc. 71, 1998 (1949).

13. D. G. Leaist and R. Lu, J. Chem. Soc., Faraday Trans. 93, 1755 (1949).

14. J. N. Agar and V. M. M. Lobo, J. Chem. Soc. Faraday Trans. 1 71, 1659 (1975).

15. V. M. M. Lobo, A. C. F. Ribeiro, and L. M. P. Verissimo, J. Mol. Liq. 78, 139 (1998).

16. V. M. M. Lobo, A. J. M. Valente, and A. C. F. Ribeiro, in Focus on Chemistry and Biochemistry, G. E. Zaikov, V. M. M. Lobo, and N. Guarrotxena, eds. (Nova Science, New York, 2003), Chap. 2, pp. 15-38. 
17. V. M. M. Lobo, Handbook of Electrolyte Solutions (Elsevier, Amsterdam, 1990).

18. D. G. Leaist and P. A. Lyons, J. Solution Chem. 13, 77 (1984).

19. D. G. Leaist and R. Lu, J. Chem. Soc., Faraday Trans. 93, 1341 (1997).

20. In, Chemistry and Physics. A Ready-Reference Book of Chemical and Physical Data, R. C. Weast, ed. (CRC, Boca Raton, FL, 1983).

21. V. Vitagliano and P. A. Lyons, J. Am. Chem. Soc. 78, 4538 (1956).

22. P. Vanysek, in CRC Handbook of Chemistry and Physics, D. R. Lide, ed. (CRC, Boca Raton, Florida, 2002), 83rd edn. 